https://www.journal-imab-bg.org

Case report

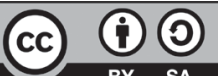

\section{SMALL BOWEL OBSTRUCTION IN TROCAR SITE HERNIA. CASE REPORT AND LITERATURE REVIEW}

\author{
Vasil Bozhkov, Plamen Chernopolsky, Rossen Madjov \\ Second Department of Surgery, UMHAT St. Marina, Medical University - Varna, \\ Bulgaria.
}

\begin{abstract}
:
The laparoscopic surgery became one of the biggest events of the modern surgery. Despite of all advantages this surgery presents new, other type complications which require special attention and different surgical approach. For the first time trocar site hernia was described from Fear in 1968 as a complication of diagnostic laparoscopy due pathology for gynecological origin. In 2004 Tonouchi invented a classification of trocar site hernias. New techniques are developed to avoid this complication.

We present a case of a female patient admitted in our department with following complaints: heaviness and pain in the abdomen, nausea, and vomiting lack of peristalsis and defecation. Couple of days ago she underwent laparoscopic myomectomy in another hospital. The imaging findings showed intestinal obstruction and incarcerated small intestinal loop incisional hernia at the topic place of the left trocar. Intraoperative findings were strangulated jejunal loop with impaired blood supply. Resection followed by primary anastomosis was performed.
\end{abstract}

Keywords: Laparoscopy, bowel injuries, postoperative hernia after laparoscopy,

\section{INTRODUCTION}

Laparoscopic surgery became one of the biggest achievements of the modern surgery. It was invented routinely in the treatment of diseases in the abdomen, retroperitoneum, thorax etc. The mini-invasive surgery led to definitely decrease of the incisional hernia which is frequent complication of the open surgery. $[1,2]$

According to literature data, the frequency rate of the trocar site hernias is lower to the conventional surgery $0,021-6 \%$. Perhaps the real incidence is higher. [1] This may be due to no-follow - up the patients, asymptomatic clinical presentation, obesitas. [3] It depends on the type of the laparoscopic procedures too it is higher when larger trocars are used (10mm, 12mm). [2, 4]

\section{CASE REPORT}

In the Second Department of Surgery a 51 years old female patient was admitted in emergency. The complaints of the patients were heaviness and pain in the abdomen, nausea, and vomiting. No bowel movements Two days ago the patient was discharged from department of gynecology where a laparoscopic myomectomy was performed. The day she left the gynecology she had discrete complaints. The physical examination showed padded, bloated abdomen tympanism on percussion and missing peristalsis. There was a hematoma on the left side of the abdomen with size $15 / 5 \mathrm{~cm}$. Rectal examination - empty ampula. X- rays and $\mathrm{CT}$ of the abdomen were performed. Dilated till $44 \mathrm{~mm}$. small intestinal loop was found in the upper abdomen. CT showed $80-90 \mathrm{~mm}$ from the navel at the left side incisional hernia, with small intestinal loop in it sized $43 / 40 \mathrm{~mm}$. with slightly thickened walls without blood supply infarction. (Fig. 1a,b.)

Fig. 1. a) X-ray - dilated small intestinal loops, b) CT - small intestinal loop subcutaneously.

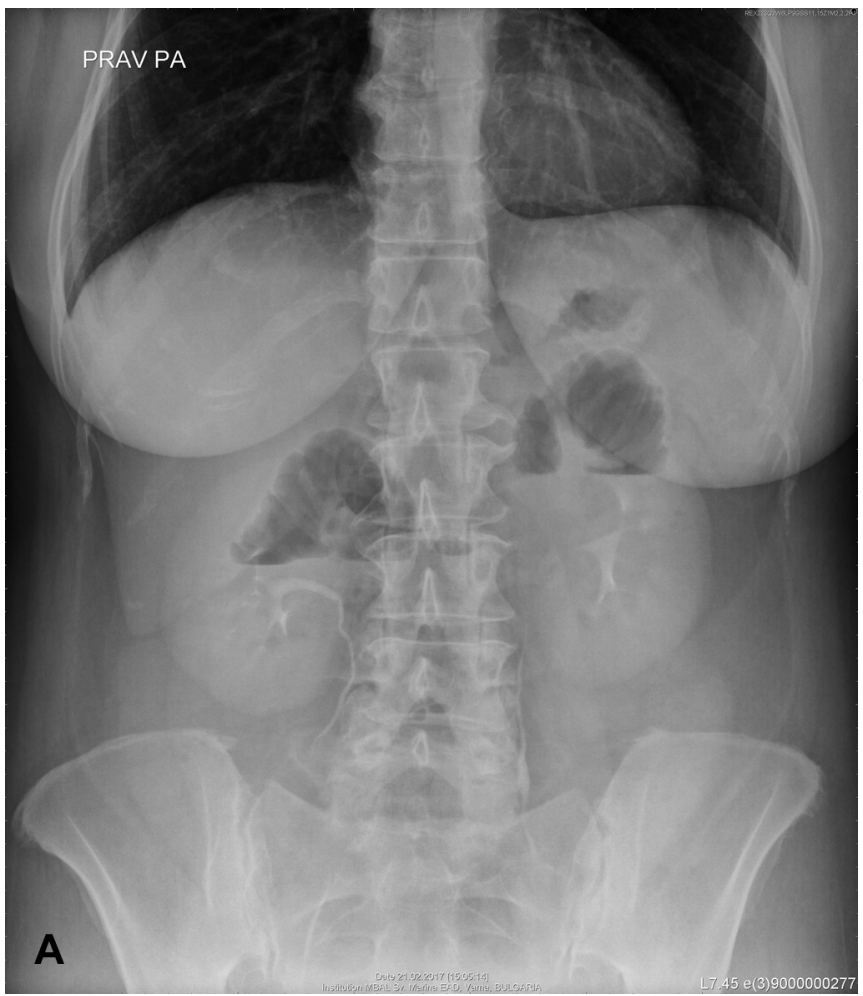




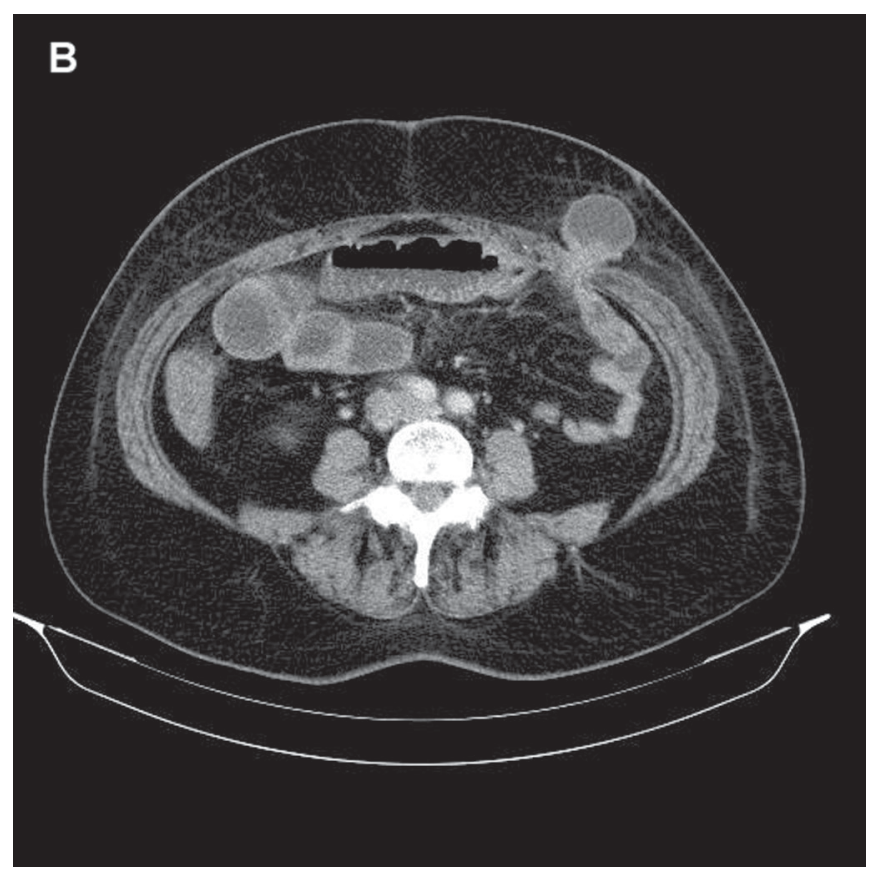

The patient was operated in emergency. Intraoperatitve finding were incarcerated small intestinal loop with bluish wall and strangulation marks. Resection of the loop was performed followed by primary anastomosis.

\section{DISCUSSION:}

The invention of the laparoscopic surgery by Müche, Mouret, Perissat, Berci, Couchieri led to fast application in surgery and became important innovation in the history of surgery. It It has an serious contribution to reducing all of the typical complications of open surgery. On the other hand, it is associated with the appereance of a new type of complications such as:

$\checkmark$ Blood vessels injuries - 0,04\% - 0,5\%

$\checkmark$ GIT injuries- $0,13 \%$

$\checkmark$ Genitourinary tract injuries $-0,025 \%$

$\checkmark$ Incisional hernias- $0,23 \%$

$\checkmark$ Metastases at the trocar sites $-0,3 \%-1,1 \%$

$\checkmark$ Gas embolism - $0.01 \%$ [5]

Trocar site hernia is a hernia which appears after mini invasive surgery at the place of the trocar. [6] !

In 2004 Tonouchi created a classification of trocar site hernias and divided them in three types. Fig. 2 [7]

$\checkmark$ Early type - defect of anterior and posterior sheath of the rectal muscle and peritoneum, which appears in the early postoperative period. The clinical presentation is with small intestinal obstruction. As an example this is incarceration Richter type. Fig. 2B

$\checkmark$ Late type - defect of anterior and posterior sheath of the rectal muscle and the peritoneum is the sac. They appear months after the laparoscopy and don't lead to small intestinal obstruction. The patients have asymptomatic lump at the place of incision.Fig. 2C

$\checkmark$ Special type - defect of the all layers of the abdominal wall with herniation of the omentum or intestine. They appear early after the procedure. Fig. 2D

Fig. 2. Trocar site hernias classication of Tonouchi 2004 [7]

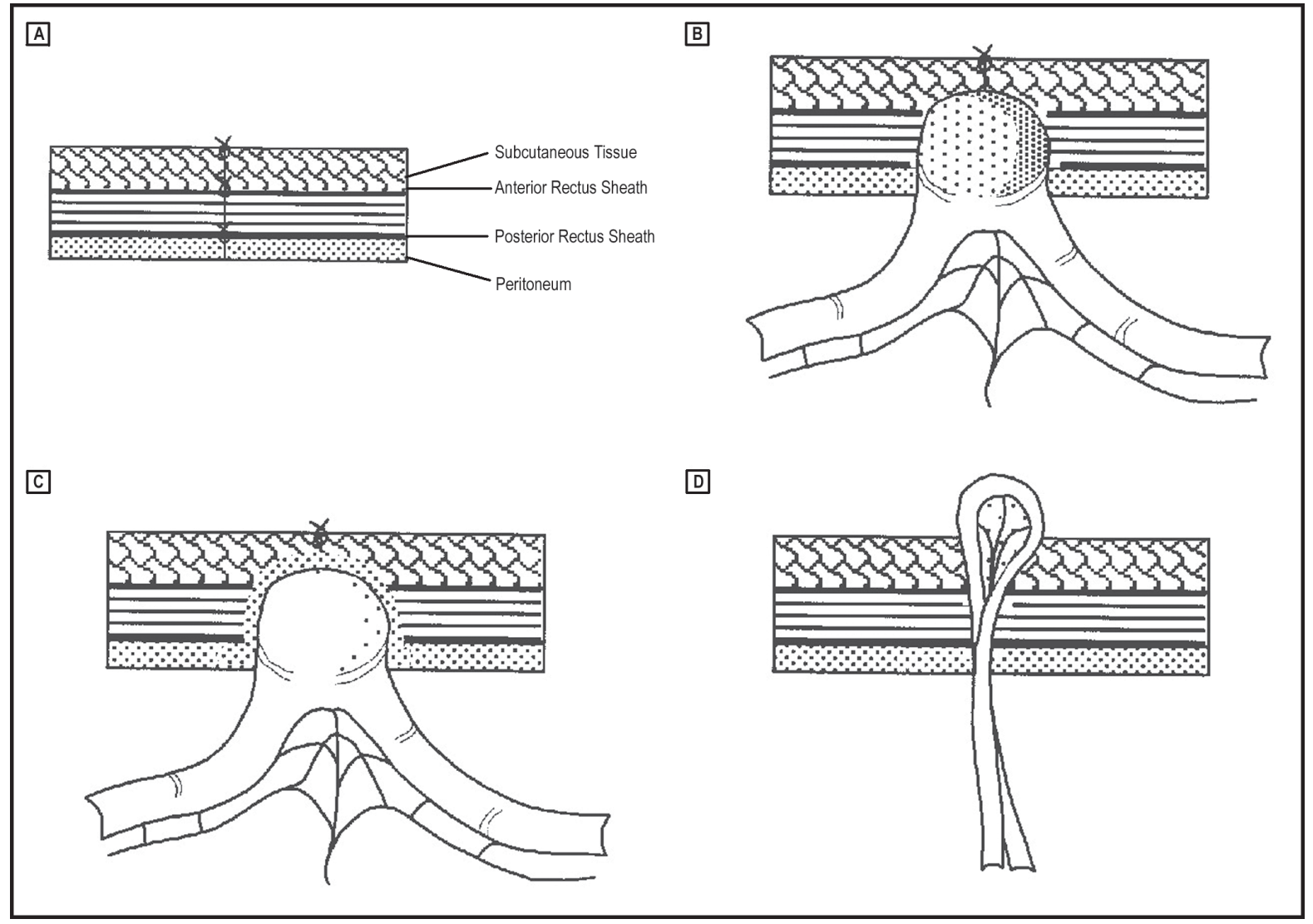


The clinical presentation of the trocar site hernias is early and appears till the $30^{\text {th }}$ day. It is a result of incarceration of omentum or small intestine in the trocar defect. The intestinal occlusion stays hidden till the presentation of acute abdomen, which requires emergency operation. [6]

In 2003 Boughey et al. described four cases of Richter's hernia after laparoscopic surgery. Two of the cases are operated laparoscopically and two with laparotomy. They concluded that is possible to perform laparoscopic hernia repair at the moment of diagnosis and if the incarcerated loop is vital. [4]

Trocar site hernias are one of the leading complications after laparoscopic hernia repair. Boldo et al. in a research from 2007 report for frequency rate of trocar site hernia of $22 \%$. They marked higher frequency in female, larger mesh, in patients with diabetes. Main reasons for appearance of these hernias they noticed: the extension of the trocar hole during the insertion of the mesh in the abdominal cavity and the postoperative retraction of the mesh after the operation. [8]

At the end of the XXth century a few studies turned special attention on problems due to the trocar design and concluded that trocars without blades don't need separated stitch of fascia of the abdominal wall. Kolata et al. prouved that the number of these defects from this type are less compared to bladed trocars in animals. [9]

Leibl et al. compared two groups patients first bladed trocars for single are used and second with conic shape trocar without blades for multiple use. The results showed postoperative hernias I $1,83 \%$ in patients where bladed single use trocars are used and $0,17 \%$ in the group where non bladed trocars are used. They prouved a reason for using conic trocars, because they permit atraumatic insertion in the abdominal cavity. $[6,10]$

Duron et al. recommend desuflation of the pneumoperitoneum through the place of insuflation before removing the trocars avoiding the involvement of the omentum and the small intestine. [11]

Tonouchi et al. considered that only closing of the fascial defect and the peritoneum prevent from trocar site hernia. [7]

The frequency rate of the trocar site hernias depends on some characteristics of the patients too like:

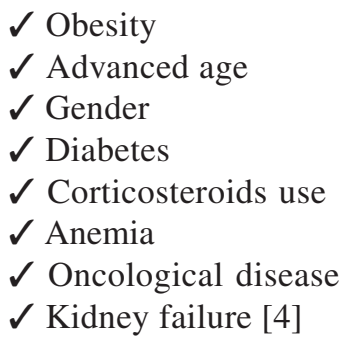

\section{CONCLUSIONS:}

The trocar hernias are potential complication of the laparoscopic surgery especially using larger trocars.

The frequency rate of the trocar site hernias is lower comparing postoperative hernias due to open surgery.

The risk factors for appearance of postoperative hernias are determinated from the surgical technique and the characteristics of the patients.

\section{REFERENCES:}

1. Boughey JC, Nottingham JM, Walls AC Richter's hernia in the laparoscopic era: four case reports and review of the literature. Surg Laparosc Endosc Percutan Tech. 2003 Feb;13(1):55-8. [PubMed]

2. Chiu CC, Lee WJ, Wang W, Wei PL, Huang MT. Prevention of trocarwound hernia in laparoscopic bariatric operations. Obes Surg. 2006 Jul;16(7):913-8. [PubMed]

3. Munro MG. Laparoscopic access: complications, technologies, and techniques. Curr Opin Obstet Gynecol. 2002 Aug;14(4):365-74. [PubMed]

4. Bowrey DJ, Blom D, Crookes PF, Bremner CG, Johansson JL, Lord $\mathrm{RV}$, et al. Risk factors and the prevalence of trocar site herniation after laparoscopic fundoplication. Surg Endosc. 2001 Jul;15(7):663-6. [PubMed]
5. Worley MJ, Slomovitz BM, Ramirez PT. Complications of laparoscopy in benign and oncologic gynecological surgery. Rev Obstet Gynecol. 2009 Summer;2(3):169-75. [PubMed]

6. Delmonaco P, Cirocchi R, La Mura F, Morelli U, Migliaccio C, Napolitano V, et al. Trocar site hernia after laparoscopic colectomy: a case report and literature review. ISRN Surg. 2011;2011:725601. [PubMed] [Crossref]

7. Tonouchi H, Ohmori Y, Kobayashi M, Kusunoki M. Trocar Site Hernia. Arch Surg. 2004 Nov;139(11):1248-56. [PubMed]

8. Boldo E, Perez de Lucia G, Aracil JP, Martin F, Escrig J, Martinez $D$, et al. Trocar site hernia after laparoscopic ventral hernia repair. Surg Endosc. 2007 May;21(5):798800. [PubMed] [Crossref]
9. Kolata RJ, Ransick M, Briggs L, Baum D. Comparison of wounds created by non-bladed trocars and pyramidal tip trocars in the pig. $J$ Laparoendosc Adv Surg Tech A. 1999 Oct;9(5):455-61. [PubMed] [Crossref]

10. Leibl BJ, Schmedt CG, Schwarz J, Kraft K, Bittner R. Laparoscopic surgery complications associated with trocar tip design: review of literature and own results. $J$ Laparoendosc Adv Surg Tech A. 1999 Apr;9(2):135-40. [PubMed] [Crossref]

11. Duron JJ, Hay JM, Msika S, Gaschard D, Domergue J, Gainant A, et al. Prevalence and mechanisms of small intestinal obstruction following laparoscopic abdominal surgery: a retrospective multicenter study. Arch Surg. 2000 Feb;135(2):208-12. [PubMed] 
Please cite this article as: Bozhkov V, Chernopolsky P, Madjov R. Small bowel obstruction in trocar site hernia. Case report and literature review. J of IMAB. 2019 Jul-Sep;25(3):2667-2670. DOI: https://doi.org/10.5272/jimab.2019253.2667

Received: 15/11/2018; Published online: 27/08/2019

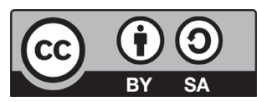

Address for correspondence:

Associate prof. dr Bozhkov MD PhD

Second department of Surgery, UMHAT Saint Marina, Varna,

1 Hr. Smirnenski blvd., Varna, Bulgaria.

e-mail: bojkov7@gmail.com 